\title{
In-vitro diffusion study of caffeine from microemulsion gel system containing grape seed oil
}

\author{
Sani Ega Priani ${ }^{*}$, Dinnanda Yussepina Wulansari, Fitrianti Darusman \\ Pharmacy Department, Bandung Islamic University (UNISBA) \\ Jln. Taman Sari 1 Bandung 40116
}

Submitted: 10-10-2020

Reviewed: 07-12-2020

Accepted: 24-02-2021

\begin{abstract}
Cellulite was identified by the orange-peel appearance of skin surface that presents in 80$90 \%$ of post-pubertal women. Caffeine and grape seed oil were known can be used as an anticellulite agent. Microemulsion systems are known could enhance the diffusion rate of drugs through the skin. This study was conducted to develop a microemulsion gel containing caffeine and grape seed oil and determine the effect of caffeine's in vitro diffusion profile. Microemulsion gel was prepared using tween 80 as a surfactant, glycerin as cosurfactant, viscolam mac 10 as a gelling agent. The preparations were evaluated by organoleptic, $\mathrm{pH}$, viscosity, rheology, spreadability, globule size, and thermodynamic stability tests. In vitro diffusion tests were performed by Franz diffusion cell. The result showed that microemulsion containing $1 \%$ of caffeine and $5 \%$ of grapeseed oil has good physical characteristics and stability with an average globule size $126 \pm 17$ $\mathrm{nm}$. Microemulsion gel system could enhance the cumulative release amount of caffeine through synthetic membrane compared with gel system. Drug release kinetics of caffeine from microemulsion gel system follows the Higuchi model.
\end{abstract}

Keywords: caffeine, grape seed oil, cellulite, microemulsion gel, Higuchi model

*Corresponding author:

Sani Ega Priani

Pharmacy Department, Bandung Islamic University

Jl. Taman Sari 1 Bandung

Email:egapriani@gmail.com 


\section{INTRODUCTION}

Cellulite is an orange-peel appearance of the skin surface that is commonly found at the thighs, buttocks, lower abdomen, and upper parts of the arms. Cellulite resulted from excessive fat storage that creates dimples the skin's surface (de Godoy et al., 2017). Previous studies showed that cellulite present in $80-90 \%$ of a post-pubertal woman (Luebberding et al., 2015). The extracellular matrix and lymphatic system disorders are also associated with cellulite pathophysiology (Sadick, 2019). Cellulite treatments are diverse, including topical agents, energy-based devices, injectable biologic medications, and also dermal fillers. The application of topical agents is the earliest approach to treat cellulite and is known to significantly reduce signs of cellulite.

Previous studies showed that caffeine and grape seed oil could be used for cellulite treatment in topical applications. Caffeine is known as the most useful and safest compound for cellulite treatment compare with other methylxanthine derivates. Caffeine is usually used in concentrations $1-2 \%$. Caffeine promoting lipolysis through inhibition of phosphodiesterase and increase adenosine monophosphate (AMP) levels in adipocytes. Caffeine stimulates the breakdown of triglycerides into glycerol and fatty acids by activating the enzyme lipase (Herman and Herman, 2012). Caffeine also has a stimulating effect on cutaneous microcirculation and supports its anti-cellulite effect (Rawlings, 2006). Grapeseed oil (Vitis vinifera L.) contains proanthocyanidins that can act as collagenase-blocking agents and prevent collagen's breakdown in cellulite conditions. The grape seed oil is usually used at a 2-7\% concentration for topical application (Rawlings, 2006).

The anti-cellulite agent must be penetrated through the skin to reach adipocytes in the dermis. Caffeine has a $\log \mathrm{P}$ value of 0.07 with hydrophilic properties and inhibits percutaneous penetration. A pharmaceutical formulation strategy must be applied to facilitate caffeine penetration through the skin (Byun et al., 2015). One formulation strategy to increase skin penetration of the drug is a microemulsion system. A microemulsion is a transparent and thermodynamically stable liquid dispersion composed containing water, surfactant, and cosurfactant with small droplets, with a size range of 5-200 nm (Singh et al., 2014). Microemulsion systems have several advantages, such as enhanced drug solubility, enhancing topical and oral availability, and can accommodate both lipophilic and hydrophilic drugs (Nastiti et al., 2017). A previous study showed that microemulsion could improve caffeine's skin permeability compared with gel and emulsion (Bolzinger et al., 2008). For topical delivery, microemulsion can be incorporated in a polymer gel base to increase skin adhesion, mentioned as microemulsion gel (Mehta et al., 2015). Microemulsion gel system known has good solubilization capacity and small droplet size that can improve skin permeability.

This research develops the microemulsion gel containing grape seed oil and caffeine as an anti-cellulite active agent with good physical characteristics. Another purpose of this research was to characterize the in vitro diffusion profile of caffeine from microemulsion gel.

\section{MATERIALS AND METHOD} Materials

The materials used in this study are Caffeine (Brataco), grape seed oil (Lansida group), tween 80 (Brataco), glycerin (Brataco), Viscolam MAC 10 ${ }^{\circledR}$ (Nardev), Triethanolamine/TEA (Brataco).

\section{Methods \\ Optimization formula of grape seed oil microemulsion}

The microemulsion formula was optimized by varying the concentration of tween 80 as surfactant and glycerin as cosurfactant (Table 1). Grapeseed oil, tween 80, glycerin were mixed at $40^{\circ} \mathrm{C}$. The water phase was then added portion-wise with continuous stirring (200 rpm) for 10 minutes. Visual appearance and percent transmittance of the preparations were observed (Priani et al., 2017). 
Table 1. Formulation of grape seed oil microemulsion

\begin{tabular}{ccccccc}
\hline Ingredients (\%w/w) & F1 & F2 & F3 & F4 & F5 & F6 \\
\hline Grape seed oil & 5 & 5 & 5 & 5 & 5 & 5 \\
Tween 80 & 30 & 30 & 30 & 35 & 35 & 35 \\
Glycerin & 25 & 30 & 35 & 25 & 30 & 35 \\
Distilled water & 40 & 35 & 30 & 35 & 30 & 25 \\
\hline
\end{tabular}

\section{Optimization formula of caffeine's microemulsion gel}

Microemulsion gel was developed based on an optimum formula of the microemulsion. Viscolam Mac 10 at concentration 1.5\% was added to convert the microemulsion system to a microemulsion gel system. Three microemulsion gel preparations were made, which were differentiated based on the concentration of caffeine used $(1 ; 1.5 ; 2 \%)$. Microemulsion gels were prepared by dissolving caffeine and distilled water and then mix with Viscolam and heated at $40^{\circ} \mathrm{C}$. Grapeseed oil, tween 80 , glycerin were mixed at $40^{\circ} \mathrm{C}$. Water phased then added portion-wise with continuous stirring (200 rpm) for 10 minutes. Triethanolamine (TEA) was added to the final mixture to reach the $\mathrm{pH}$ of preparation 6-7 (Table 2). Visual appearance and percent transmittance evaluation was conducted to screening the optimum concentration of caffeine in microemulsion gel preparation (Badawi et al., 2009).

\section{Physical evaluation of microemulsion gel}

The physical evaluation carried out on the microemulsion gel preparation included: visual observation, $\mathrm{pH}$, viscosity and rheology, spreadability, percent transmittance, and globule size determinations. The systems were visually observed for homogeneity, fluidity, and optical clarity (Sabale and Vora, 2012). the $\mathrm{pH}$ of preparations was performed using a $\mathrm{pH}$ meter(Metler Toledo, Seven Compact ${ }^{\mathrm{TM}}$ S220) (Sabale and Vora, 2012).

The rheological properties determination of microemulsion gel was performed by Brookfield digital viscometer (RV D 220). The viscosity of preparation was measured at varying rotational speeds of the spindle $(10 ; 20 ; 50 ; 100 ; 50 ; 20 ; 10 \mathrm{rpm})$. The viscosity measurement was done using spindle number 62 (Sabale and Vora, 2012). The microemulsion gel's spreadability was measured by spreading $1 \mathrm{~g}$ of the gel on a glass plate, and then a second glass plate was employed. 500 grams of weight was store on the upper glass plate for $5 \mathrm{~min}$. The circle's diameter after the spreading of the microemulsion gel was measured (Nikumbh et al., 2015).

Transparency of microemulsion gels was determined by $\%$ transmittance measurement using spectrophotometer UV/Vis (Shimadzu UV-1800) at $650 \mathrm{~nm}$ using distilled water as a blank. Globule size of microemulsion gel was determined using Particle Size Analyzer (Beckman Coulter LS 13 320) directly without dilution (Shinde et al., 2012).

\section{Thermodynamic stability tests}

Thermodynamic stability tests were performed by three evaluation steps: centrifugation, heating cooling, and freeze-thaw tests. Microemulsion gel was centrifuged at $3750 \mathrm{rpm}$ for $30 \mathrm{~min}$. At heating cooling tests, the preparation is stored at temperatures $4^{\circ} \mathrm{C}$ and $40^{\circ} \mathrm{C}$ for a minimum of 24 hours for each temperature and carried out for three-cycle. At freeze-thaw tests, the preparation is stored at temperatures $4^{\circ} \mathrm{C}$ and $40^{\circ} \mathrm{C}$ for a minimum of 24 hours at each temperature and carried out for three-cycle. Physical instabilities such as creaming, phase separation, and sedimentation were assessed at the end of each cycle (Ali et al., 2014).

\section{In-vitro diffusion study}

The caffeine calibration curve was determined at series concentration 3, 5, 7, 9, 11, dan 13 $\mu \mathrm{g} / \mathrm{mL}$ at phosphate buffer $\mathrm{pH} 7.4$ at maximum wavelength $272.6 \mathrm{~nm}$. The kinetics of the in vitro release of caffeine from microemulsion gel was evaluated and compared with gel formulation 
( $1 \%$ of caffeine on $8 \%$ vascular gel). The studies were conducted using HT-Tuffryn membrane in Franz diffusion cells with a diffusional area of $3.14 \mathrm{~cm}^{2}$ and $0.2 \mu \mathrm{m}$ pore size. The receiver compartment was filled with $15 \mathrm{~mL}$ of phosphate buffer at a pH $7.4\left(37 \pm 0.5{ }^{\circ} \mathrm{C}, 600 \mathrm{rpm}\right) .0 .5$ gram of preparations were applied directly into the membrane. $2.0 \mathrm{~mL}$ samples of the receiving compartment were collected at 30, 45, 60, 90, 120,150, dan 180 minutes. The aliquots' absorption was measured using spectrophotometry (Shimadzu UV-1800) at the maximum wavelength of caffeine $(272.6 \mathrm{~nm})$. The receptor phase was replaced at each sampling time by $2.0 \mathrm{~mL}$ of phosphate buffer. (Figueiredo et al., 2016).

The total amount of caffeine that penetrated, per diffusion area $\left(\mu \mathrm{g} / \mathrm{cm}^{2}\right)$, was determined using the following standard formula (Iskandarsyah et al., 2017):

$$
Q=\frac{\left[C n \cdot V+\sum_{i=1}^{n-1} \mathrm{Ci} . S\right]}{A}
$$

Qn = total caffeine that penetrated per diffusion area $\left(\mu \mathrm{g} / \mathrm{cm}^{2}\right)$

$\mathrm{Cn}=$ concentration of caffeine $(\mu \mathrm{g} / \mathrm{mL})$

$\mathrm{V} \quad=$ volume of the Franz diffusion cell

$\sum_{i=1}^{n-1} \mathrm{Ci}=$ concentration of caffeine $(\mu \mathrm{g} / \mu \mathrm{L})$ in the first sample until $\mathrm{n}-1$

$\mathrm{S} \quad=$ sampling volume $(\mathrm{mL})$

A $=$ membrane area $\left(\mathrm{cm}^{2}\right)$

The kinetic diffusion profile of caffeine was evaluated by fitting the experimental data to each release kinetics equation. Linear regression analyses were made to zero order, first order, and Higuchi models. The selection of an appropriate kinetic diffusion model is based on each equation's correlation coefficient values ( 1) (Cojocaru et al., 2015).

\section{RESULT AND DISCUSSION}

This research was started by developing the microemulsion system of grapeseed oil as the oil phase and an active ingredient. Grapeseed oil is used at a concentration of 5\% since that concentration gives an anti-cellulite effect for topical application (Herman and Herman, 2012). Using grapeseed oil as the oil phase will increase the anti-cellulite effect of the caffeine microemulsion. Tween 80 is used as a surfactant. Tween 80 is a small molecular nonionic surfactant used in microemulsion production with low skin toxicity (Cho et al., 2008). Tween 80 has good miscibility with grape seed oil better than another surfactant (tween 20, tween 60, and hydrogenated castor oil) (Komaiko and Mcclements, 2016). Glycerin was used as a cosurfactant that caused has good miscibility with grape seed oil compared with ethanol, propylene glycol, polyethylene glycol, and Transcutol based on our previous study. Glycerin is generally regarded as a nontoxic and nonirritant material. Glycerin, as cosurfactant was added to allows the flexibility of interfacial film and reduces interfacial tension sufficiently to form a microemulsion.

The microemulsion formula optimization results showed that the formulas F1, F2, and F3 form cloudy preparations. Formulas F4, F5, and F6 produce transparent microemulsion with the highest percent transmittance value at F6 $(98.7 \pm 0.7 \%)$. Since percent transmittance indicates the homogeneity and clarity of formulation, F6 was selected as a basic microemulsion gel formula. Surfactant and cosurfactant concentration in F6 sufficient to form a stable interfacial system in the formation of micro globules. Viscolam mac 10 was added as a gelling agent to the microemulsion gel system. Caffeine was added to the microemulsion gel system in three concentrations $1,1.5$, and $2 \%$, since caffeine's effective concentration as anti-cellulite is $1-2 \%$. Based on physical evaluations,

Pharmaciana Vol. 11, No. 1, March 2021, Page. 81-90 
caffeine's maximum concentration that could be added to the microemulsion gel system is $1 \%$ (Table 2).

Table 2. Formulation of caffeine microemulsion gel

\begin{tabular}{cccc}
\hline Ingredients (\% w/w) & F6A & F6B & F6C \\
\hline Caffeine & 1 & 1.5 & 2 \\
Grape seed oil & 5 & 5 & 5 \\
Tween 80 & 35 & 35 & 35 \\
Glycerin & 35 & 35 & 35 \\
Viscolam MAC 10 & 1.5 & 1.5 & 1.5 \\
TEA & $\mathrm{Qs}$ & $\mathrm{qs}$ & $\mathrm{qs}$ \\
Distilled water until & 100 & 100 & 100 \\
Visual appearance & Transparent & Turbid & Turbid \\
\% transmittance & $98.2 \pm 0.6$ & $<10$ & $<10$ \\
\hline
\end{tabular}

The final formula of the microemulsion gel according to formula F6A, since the transmittance value $>95 \%$. Some evaluations were conducted to the final preparation, including visual observation, $\mathrm{pH}$, viscosity, rheology, spreadability, and globule size measurements. The result shows that the preparation has a good physical characteristic (Table 3). The transparent appearance of preparation shows the excellent characteristic of microemulsion gel. The $\mathrm{pH}$ of preparation appropriate with optimum $\mathrm{pH}$ for topical application (4-7). Viscosity value at $50 \mathrm{rpm}$ appropriate with optimum gel system viscosity (2000-4000 cps) (Garg et al., 2002). The system shows non-Newtonian rheological property with the pseudoplastic flow since the gel's viscosity decreases with increasing shear rate (Figure 1). Such characteristic is desired for topical use of pharmaceutical and cosmetic products. Pseudoplastic can be expected to exhibit better spreadability (Mohsin et al., 2016). The spreadability of the preparation appropriate with optimal value for semisolid preparation is 5-7 cm (Garg et al., 2002). Globule size measurement shows that the system could be categorized as a microemulsion gel system since it has an average globule size of $<200 \mathrm{~nm}$. The curve in Figure 2 shows the globule's narrow size distribution (Subongkot and Ngawhirunpat, 2017).

Table 3. Result of microemulsion gel evaluations (F6A)

\begin{tabular}{cc}
\hline Parameters & Results \\
\hline Visual observations & Yellowish transparent, medium consistency \\
pH & $6.95 \pm 0.09$ \\
Viscosity (at $50 \mathrm{rpm})$ & $2482.33 \pm 8.49 \mathrm{cps}$ \\
Rheology & Pseudoplastic \\
Spreadability & $6.60 \pm 0.06 \mathrm{~cm}$ \\
Globule size & $126 \pm 17 \mathrm{~nm}$ \\
Thermodinamic stability & Stabile \\
study & \\
\hline
\end{tabular}

Thermodynamic stability is one of the advantages of microemulsions that distinguishes it from macroemulsions. The test was conducted in three steps, including centrifugation, heating cooling, and freeze-thaw tests. The thermodynamic stability test showed that caffeine microemulsion has good physical stability (Table 3). System instability such as phase separation, coalescence, and sedimentation did not occur after the stability test was carried out (Moghimipour et al., 2013). 


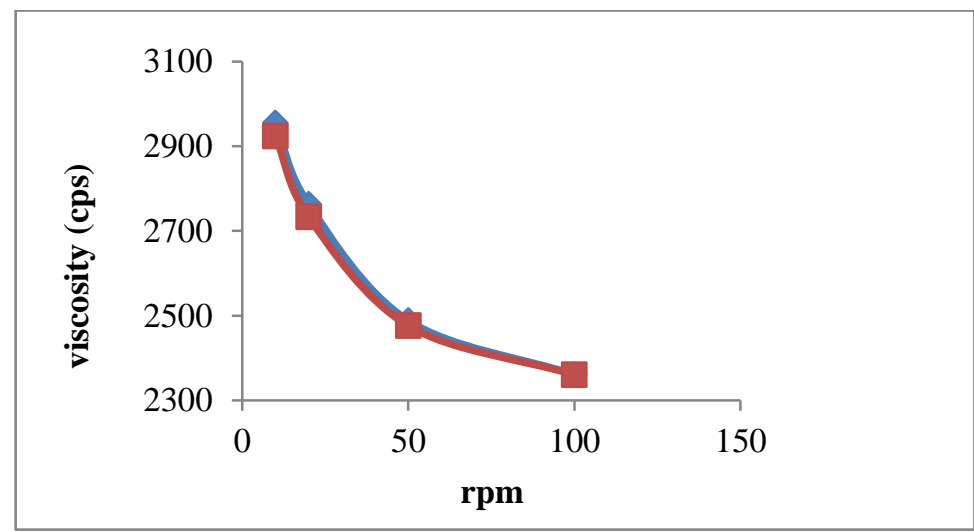

Figure 1. Rheology of caffeine microemulsion gel

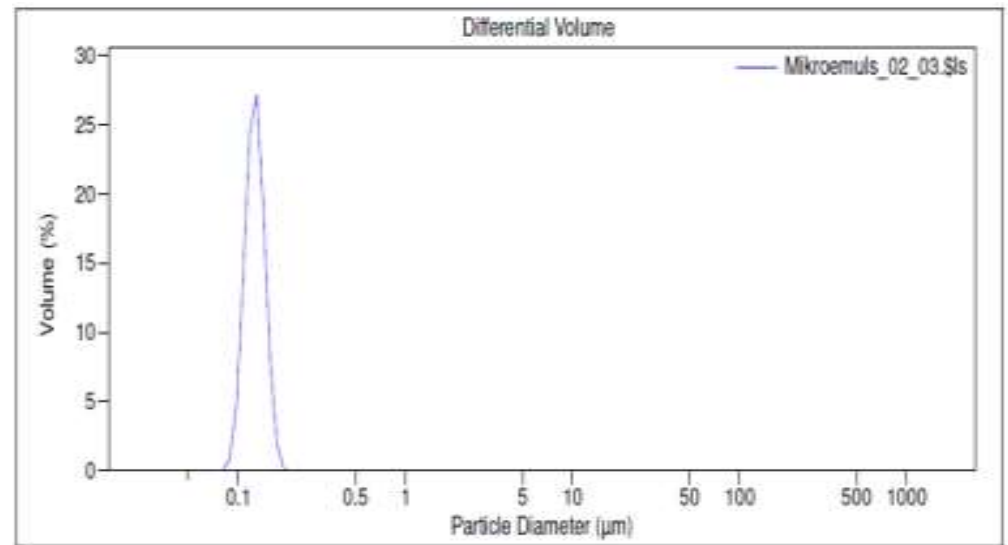

Figure 2. The globule size distribution of caffeine microemulsion gel

In-vitro diffusion study was carried out using Franz diffusion cell. Diffusion of caffeine from microemulsion gel formulation was compared with gel formulation. The gel was made using Viscolam mac 10, a similar gelling agent used in microemulsion gel. A diffusion study showed that the microemulsion gel system could enhance skin diffusion of caffeine compared with the gel (Figure 3). There are various mechanisms of the microemulsion system that could enhance skin diffusion of caffeine. Microemulsion could increase transdermal drug permeation. Microemulsion reduces globule size and provides more surface area to release drugs and increase drug release rate. Various components of microemulsion also have a penetration-enhancing effect on the drug. Microemulsion containing surfactant and cosurfactant at a high concentration can act as penetrant enhancers. (Mahore et al., 2017). 


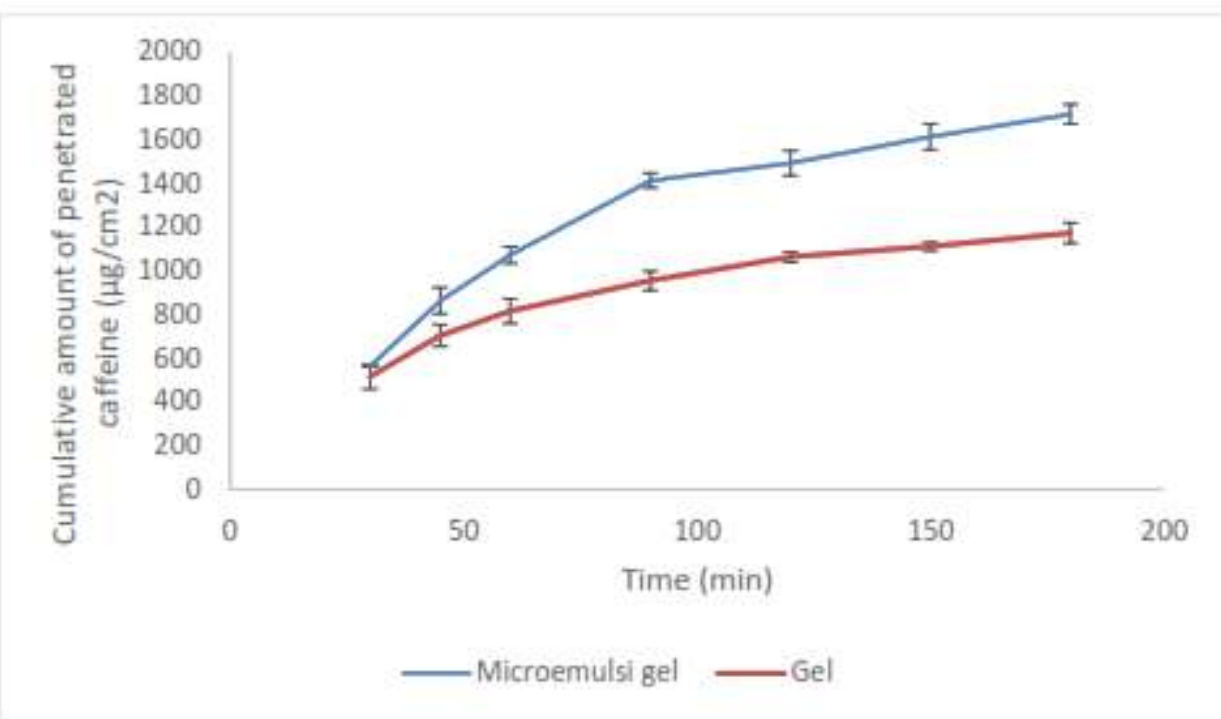

Figure 3. The cumulative amount of penetrated caffeine from the preparation

Linear regression analyses were employed for the release kinetic study (Table 4 and Figure 4). The best fit was found with the Higuchi kinetics model (the best value of correlation coefficient). In the Higuchi model, the process of releasing substances refers to simple laws of diffusion. In the Higuchi model, the drug release process does not occur due to erosion or swelling of the matrix but occurs through a diffusion process (Panapisal et al., 2012). Many drugs in the microemulsion system follow Higuchi kinetic model, including miconazole nitrate, silymarin, minoxidil, clotrimazole, and olanzapine (Shahzadi et al., 2014).

Table 4. Kinetic release model of caffeine from microemulsion gel system

\begin{tabular}{ccccc}
\hline Model & Equation Model & X value & Y value & $\mathbf{R}^{2}$ \\
\hline Zero-order & $\mathrm{Q}_{\mathrm{t}} / \mathrm{Q}_{0}=\mathrm{Ko} \cdot \mathrm{t}$ & Time & $\mathrm{Q}$ & 0.891 \\
First Order & $\mathrm{Ln}\left(\mathrm{Q}_{\mathrm{t}}-\mathrm{Q}_{0}\right)=\mathrm{K}_{1} \cdot \mathrm{t}$ & Time & $\mathrm{Ln} \mathrm{Q}$ & 0.796 \\
Higuchi & $\mathrm{Q}_{\mathrm{t}} / \mathrm{Q}_{0}=\mathrm{K}_{\mathrm{H}} \cdot \mathrm{t}^{1 / 2}$ & $\begin{array}{c}\text { The square root of } \\
\text { time }\end{array}$ & $\mathrm{Q}$ & 0.950 \\
\hline
\end{tabular}

Q: Cumulative drug release $\left(\mu \mathrm{g} / \mathrm{cm}^{2}\right)$

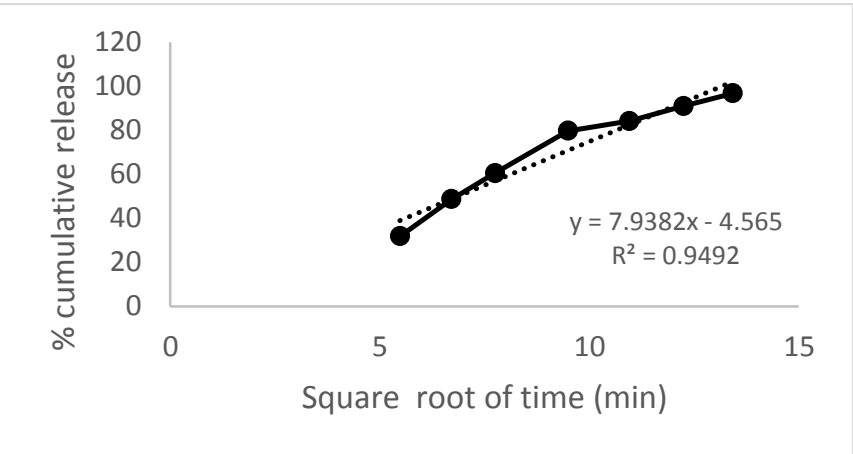

Figure 4. Diffusion kinetic study of microemulsion gel (Higuchi model) 


\section{CONCLUSION}

Microemulsion containing $1 \%$ caffeine and 5\% of grapeseed oil has good physical characteristics and stability with an average globule size of $126 \pm 17 \mathrm{~nm}$. Microemulsion gel system could increase the cumulative release amount of caffeine compared with gel formulation. Release kinetic of caffeine in microemulsion gel system follow Higuchi model.

\section{ACKNOWLEDGEMENT}

The authors wish to thank Research Centre Bandung Islamic University (LPPM UNISBA) for funding this research.

\section{REFERENCES}

Ali, M. S., Alam, M. S., Alam, N., \& Siddiqui, M. R. (2014). Preparation, characterization and stability study of dutasteride loaded nanoemulsion for treatment of benign prostatic hypertrophy. Iranian Journal of Pharmaceutical Research, 13(4), 1125-1140. https://doi.org/10.22037/ijpr.2014.1563

Badawi, A. A., Nour, S. A., Sakran, W. S., \& El-Mancy, S. M. S. (2009). Preparation and evaluation of microemulsion systems containing salicylic acid. AAPS PharmSciTech, 10(4), 1081-1084. https://doi.org/10.1208/s12249-009-9301-7

Bolzinger, M. A., Briançon, S., Pelletier, J., Fessi, H., \& Chevalier, Y. (2008). Percutaneous release of caffeine from microemulsion, emulsion and gel dosage forms. European Journal of Pharmaceutics and Biopharmaceutics, 68(2), 446-451. https://doi.org/10.1016/j.ejpb.2007.10.018

Byun, S. Y., Kwon, S. H., Heo, S. H., Shim, J. S., Du, M. H., \& Na, J. I. (2015). Efficacy of slimming cream containing 3.5\% water-soluble caffeine and xanthenes for the treatment of cellulite: Clinical study and literature review. Annals of Dermatology, 27(3), 243-249. https://doi.org/10.5021/ad.2015.27.3.243

Cho, Y. H., Kim, S., Bae, E. K., Mok, C. K., \& Park, J. (2008). Formulation of a cosurfactant-free O/W microemulsion using nonionic surfactant mixtures. Journal of Food Science, 73(3). https://doi.org/10.1111/j.1750-3841.2008.00688.x

Cojocaru, V., Ranetti, A. E., Hinescu, L. G., Ionescu, M., Cosmescu, C., Poștoarcă, A. G., \& Cinteză, L. O. (2015). Formulation and evaluation of in vitro release kinetics of na3cadtpa decorporation agent embedded in microemulsion-based gel formulation for topical delivery. Farmacia, 63(5), 656-664.

de Godoy, J. M. P., de Godoy, A. C. P., \& Godoy, M. de F. G. (2017). Considering the hypothesis of the pathophysiology of cellulite in its treatment. Dermatology Reports, 9(2), 41-42. https://doi.org/10.4081/dr.2017.7352

Figueiredo, K. A., Neves, J. K. O., da Silva, J. A., de Freitas, R. M., \& Carvalho, A. L. M. (2016). Phenobarbital loaded microemulsion: Development, kinetic release and quality control. Brazilian Journal of Pharmaceutical Sciences, 52(2), 251-264. https://doi.org/10.1590/S1984-82502016000200003

Garg, A., Aggarwal, D., Garg, S., \& Singla, A. K. (2002). Spreading of semisolid formulations: An update. In Pharmaceutical Technology North America (Vol. 26, Issue 9, pp. 84-105).

Herman, A., \& Herman, A. P. (2012). Caffeine's mechanisms of action and its cosmetic use. In Skin Pharmacology and Physiology (Vol. 26, Issue 1, pp. 8-14). https://doi.org/10.1159/000343174

Iskandarsyah, I., Puteri, A. W., \& Ernysagita, E. (2017). Penetration test of caffeine in ethosome and desmosome gel using an in vitro method. International Journal of Applied Pharmaceutics, 9, 120-123. https://doi.org/10.22159/ijap.2017.v9s1.69_76

Komaiko, J. S., \& Mcclements, D. J. (2016). Formation of Food-Grade Nanoemulsions Using Low-Energy Preparation Methods: A Review of Available Methods. Comprehensive Reviews 
in Food Science and Food Safety, 15(2), 331-352. https://doi.org/10.1111/1541-4337.12189

Luebberding, S., Krueger, N., \& Sadick, N. S. (2015). Cellulite: An Evidence-Based Review. In American Journal of Clinical Dermatology (Vol. 16, Issue 4, pp. 243-256). https://doi.org/10.1007/s40257-015-0129-5

Mahore, J. G., Suryawanshi, S. D., Shirolkar, S. V., \& Deshkar, S. S. (2017). Enhancement of percutaneous delivery of dapsone by microemulsion gel. Journal of Young Pharmacists, 9(4), 507-512. https://doi.org/10.5530/jyp.2017.9.99

Mehta, D. P., Rathod, H. J., Shah, D. P., \& Shah, C. N. (2015). A review on microemulsion based gel: A recent approach for topical drug delivery system. In Research Journal of Pharmacy and Technology (Vol. 8, Issue 2, pp. 118-126). https://doi.org/10.5958/0974360X.2015.00021.9

Moghimipour, E., Salimi, A., \& Eftekhari, S. (2013). Design and characterization of microemulsion systems for naproxen. Advanced Pharmaceutical Bulletin, 3(1), 63-71. https://doi.org/10.5681/apb.2013.011

Mohsin, S., Akhtar, N., Mahmood, T., Khan, H., \& Mustafa, R. (2016). Formulation and stability of topical water in oil emulsion containing corn silk extract. Tropical Journal of Pharmaceutical Research, 15(6), 1115-1121. https://doi.org/10.4314/tjpr.v15i6.1

Nastiti, C. M. R. R., Ponto, T., Abd, E., Grice, J. E., Benson, H. A. E., \& Roberts, M. S. (2017). Topical nano and microemulsions for skin delivery. In Pharmaceutics (Vol. 9, Issue 4). https://doi.org/10.3390/pharmaceutics9040037

Nikumbh, K. V., Sevankar, S. G., \& Patil, M. P. (2015). Formulation development, in vitro and in vivo evaluation of microemulsion-based gel loaded with ketoprofen. Drug Delivery, 22(4), 509-515. https://doi.org/10.3109/10717544.2013.859186

Panapisal, V., Charoensri, S., \& Tantituvanont, A. (2012). Formulation of microemulsion systems for dermal delivery of silymarin. AAPS PharmSciTech, 13(2), 389-399. https://doi.org/10.1208/s12249-012-9762-y

Priani, S. E., Mela, K. A., \& Lukmayani, Y. (2017). Development Sunscreen Microemulsion Gel Containing n-Hexane Fraction of Mangosteen Pericarp (Garcinia mangostana Linn.). Research Journal of Pharmaceutical, Biological and Chemical Sciences, 8, 229-235.

Rawlings, A. V. (2006). Cellulite and its treatment. In International Journal of Cosmetic Science (Vol. 28, Issue 3, pp. 175-190). https://doi.org/10.1111/j.1467-2494.2006.00318.x

Sabale, V., \& Vora, S. (2012). Formulation and evaluation of microemulsion-based hydrogel for topical delivery. International Journal of Pharmaceutical Investigation, 2(3), 140. https://doi.org/10.4103/2230-973x.104397

Sadick, N. (2019). Treatment for cellulite. In International Journal of Women's Dermatology (Vol. 5, Issue 1, pp. 68-72). https://doi.org/10.1016/j.ijwd.2018.09.002

Shahzadi, I., Irfan Masood, M., Chowdhary, F., Ahmad Anjum, A., Awais Nawaz, M., Maqsood, I., \& Quaid Zaman, M. (2014). Microemulsion formulation for topical delivery of miconazole nitrate. International Journal of Pharmaceutical Sciences Review and Research, 24(2), 3036.

Shinde, U., Pokharkar, S., \& Modani, S. (2012). Design and evaluation of microemulsion gel system of nadifloxacin. Indian Journal of Pharmaceutical Sciences, 74(3), 237-247. https://doi.org/10.4103/0250-474X.106066

Singh, P. K., Kashif Iqubal, M., Shukla, V. K., \& Shuaib, M. (2014). Microemulsions: Current Trends in Novel Drug Delivery Systems. Journal of Pharmaceutical, Chemical and Biological Sciences Journal of Pharmaceutical, Chemical and Biological Sciences Journal of Pharmaceutical, Chemical and Biological Sciences, 1(11), 39-5139. http://www.jpcbs.info

Subongkot, T., \& Ngawhirunpat, T. (2017). Development of a novel microemulsion for oral absorption enhancement of all-trans retinoic acid. International Journal of Nanomedicine, 12, 5585-5599. https://doi.org/10.2147/IJN.S142503 
